a. Department of Intensive Care of Sanatorio Allende, Córdoba, Argentina.

b. Department of Intensive Care of Hospital de Niños de la Santísima Trinidad (HNST), Córdoba, Argentina.

c. Department of Intensive Care of Hospital General de Niños Dr. Pedro de Elizalde (HGNPE), Autonomous City of Buenos Aires, Argentina.

d. Department of Intensive Care of Sanatorio Sagrado Corazón, Autonomous City of Buenos Aires, Argentina.

e. Department of Intensive Care of Hospital Infantil Municipal, Córdoba, Argentina.

f. Department of Intensive Care of Hospital de Pediatría SAMIC "Prof. Dr. Juan P. Garrahan," Autonomous City of Buenos Aires, Argentina.

g. Department of Intensive Care of Hospital Dr. Guillermo Rawson, San Juan, Argentina.

h. Coordinating Agency for Organ and Tissue Procurement for Transplantation of Córdoba, Córdoba, Argentina.

E-mail address: Pedro Taffarel, M.D.: pedrotaffarel@hotmail. com

Funding:

None.

Conflict of interest: None.

Received: 2-24-2017 Accepted: 7-11-2017

\title{
Brain death and organ donation in Argentine pediatric intensive care units. A multicenter study
}

\author{
Germán Bonetto, M.D., , ${ }^{a, b}$ Pedro Taffarel, M.D., ,,$d$ Melisa Gamerman, M.D., ${ }^{b, e}$ \\ Facundo Jorro Barón, M.D., ${ }^{c}$ Carolina Gaviña, M.D. ${ }^{f}$ Laura Flores, M.D. ${ }^{f}$ \\ Emanuel Fernández, M.D., ${ }^{g}$ Andrea Zifferman, M.D., ${ }^{d, f}$ Gustavo Debaisi, M.D., \\ Marcelo Acerenza, M.D., ,ff Jorge Selandari, M.D., Luis Landry, M.D. ${ }^{f}$ \\ Ariel Cacciamano, M.D., ${ }^{e}$ Alfredo Clavel, M.D.,, Patricia Capocasa, M.D., \\ Bernardo Calvo, M.D. ${ }^{a}$ and Marcial Angos, M.D. ${ }^{h}$
}

\section{ABSTRACT}

Brain death (BD) is a condition determined by the complete and irreversible absence of brain functions. Maintenance of vital functions creates an opportunity for organ donation.

A retrospective study was carried out in 7 pediatric intensive care units of Argentina (from $1 / 1 / 2013$ to $9 / 30 / 2016$ ) to determine the incidence of clinical and certified $\mathrm{BD}$, and the proportion of effective transplantations.

Among deceased patients, 19.14\% (147/768) met the clinical requirements for $\mathrm{BD}$, and the main cause of $\mathrm{BD}$ was multiple trauma. $\mathrm{BD}$ was certified in $13.4 \%$ of deceased patients (103); an electroencephalogram and an apnea test were the most commonly used ancillary methods. Organ maintenance time was 24 hours.

A total of 87 families were approached for donation; 59 were rejected (they were not suitable or refused). Effective donors accounted for $25 \%(26 / 103)$ of patients with certified BD and 72 patients received solid organs.

Key words: brain death, donation, transplantation, pediatric intensive care units.

http: / / dx.doi.org/10.5546/ aap.2018.eng.e54

To cite: Bonetto G, Taffarel P, Gamerman M, et al. Brain death and organ donation in Argentine pediatric intensive care units. A multicenter study. Arch Argent Pediatr 2018;116(1):e54-e60.

\section{INTRODUCTION}

The pediatric intensive care unit (PICU) is the most common location where pediatric patients die, and a percentage of such deaths corresponds to brain death (BD).

$\mathrm{BD}$ is a condition determined by the complete and irreversible absence of function in the brain hemispheres and brain stem, ${ }^{1}$ invariably followed by cardiac arrest. During this process, pathophysiological changes in the cardiovascular and respiratory systems occur and metabolic and hormonal alterations follow.
An early diagnosis of BD in accordance with the guidelines ${ }^{2}$ (see Figure 1), maintenance of vital functions, and correction of changes may create an opportunity for organ donation.

In our country, Argentina, articles 23 and 24 of Law No. 24193 establish the bases for the diagnosis of death in accordance with neurological criteria and assigns the National Institute for Organ and Tissue Procurement for Transplantation (Instituto Nacional Central Único Coordinador de Ablación e Implante, INCUCAI) as the advisory agency for the National Ministry of Health and Social Action on this matter. This institute drafted the diagnostic protocol for death in accordance with neurological criteria. ${ }^{2}$

The incidence of BD at the PICU accounts for approximately $16 \%$ of deaths. ${ }^{3,4}$ The most common cause of BD is trauma. ${ }^{5}$

In the field of pediatrics, the need for solid organ donations has increased worldwide. This age group accounts for $2 \%$ of patients in the waiting lists of the United Kingdom and $1.5 \%$ of the United States of America (USA). ${ }^{6}$ Preventive medicine, disease chronification, advancements in vital support, and the scarce case reporting of living related donors in pediatrics have led to an increased unmet need for solid organ transplantations, ${ }^{7}$ accompanied by shortcomings in the donation management process in this age group. ${ }^{8}$

In this scenario, the early suspicion 


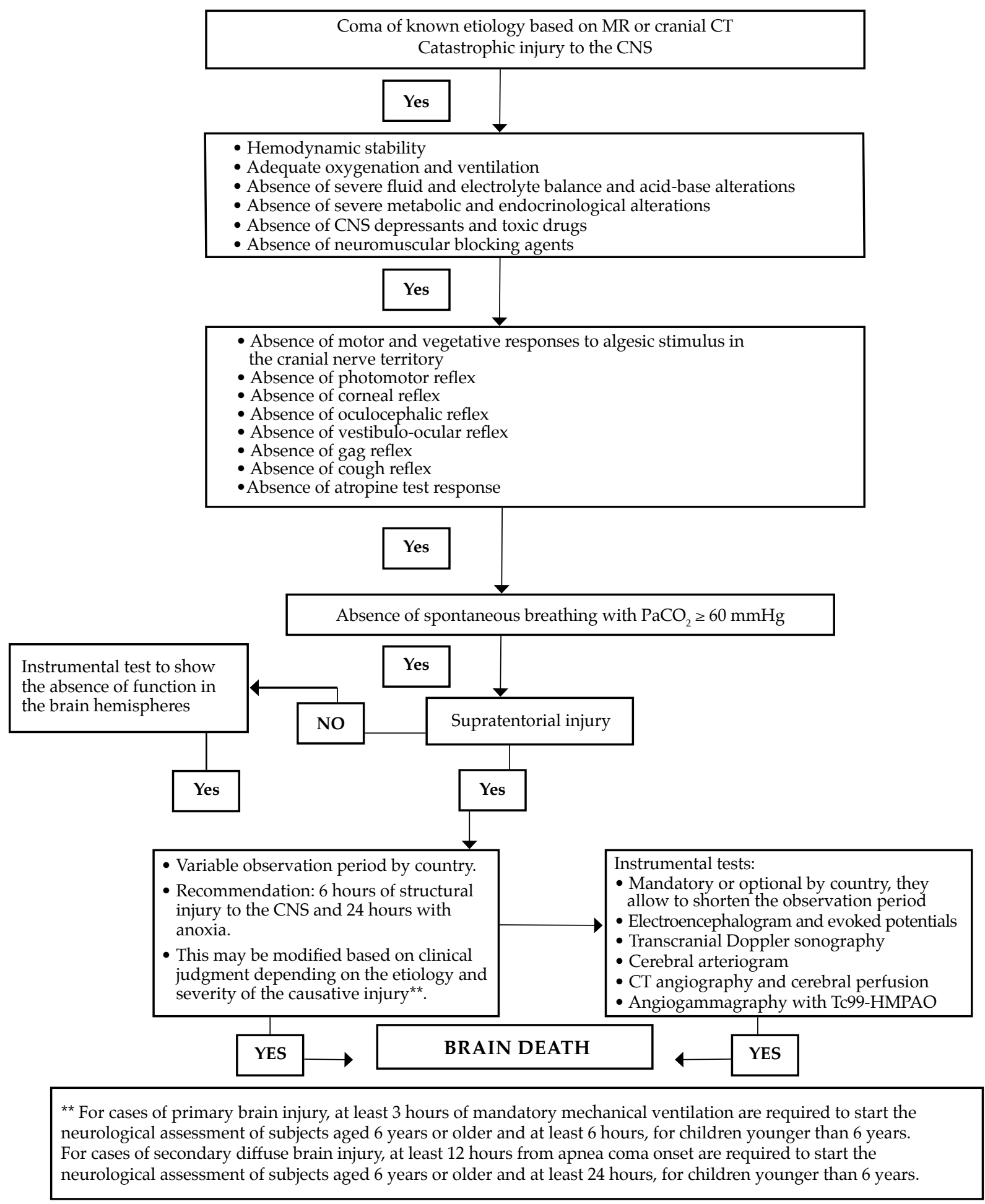

MR: medical record; CT: computed tomography; CNS: central nervous system; PaCO2: partial pressure of carbon dioxide; EEG: electroencephalogram.

Obtained and modified from Abaroa. ${ }^{1}$ 
of BD becomes mandatory so as to activate resources targeted at $\mathrm{BD}$ certification, but there is discrepancy on how to get to it. ${ }^{9,10}$

In this regard, different research lines have made an effort to enhance BD diagnosis and the organ donation management process in its entirety.

No reports have been found in the local bibliography about BD case reporting at Argentine PICUs or transplantation effectiveness.

\section{OBJECTIVES}

- To determine the incidence of clinical and certified BD at the PICU.

- To determine the proportion of effective transplantations out of all potential donors.

\section{Study design}

This was a retrospective and multicenter study conducted between January 2013 and September 2016 at the PICUs selected by convenience from the following public and private hospitals: Hospital de Niños Santísima Trinidad (HNST) in Córdoba, Hospital Infantil Municipal (HIM) in Córdoba, Hospital General de Niños Dr. Pedro de Elizalde (HGNPE), Nacional "Prof. Dr. Juan P. Garrahan" (HNJPG), Hospital Dr. Guillermo Rawson, in San Juan, Sanatorio Allende (SA), in Córdoba, and Sanatorio Sagrado Corazón (SC) in Buenos Aires.

\section{Population universe and sample}

All patients deceased at 7 PICUs during the study period who met the clinical and/or instrumental criteria of BD, as shown in Figure 1.

\section{Methodology}

The outcome measures analyzed at the time of admission to the PICU were age (months), sex, and reason for admission.

The main cause related to BD was grouped into the following categories: multiple trauma (accident on the street, fall, gunshot wound -this category included severe traumatic brain injury-), central nervous system (CNS) infection with documented microorganism, hypoxia/cerebral ischemia if the mechanism leading to BD was asphyxia (choking, hanging) or the consequence of situations that led to oxygen $\left(\mathrm{O}_{2}\right)$ deprivation (status epilepticus, following a cardiopulmonary arrest, sudden death, carbon monoxide poisoning, etc.), and if neuroimaging showed injury compatible with this mechanism (infarction, generalized edema, loss of differentiation between gray and white matter, etc.), stroke, CNS tumor (observed in neuroimaging), liver failure (international normalized ratio [INR] $>1.8$ or factor $\mathrm{V}<50 \%$ ) and, finally, "others." The proportion of patients with BD who presented intracranial hypertension (IH) confirmed with intracranial pressure monitoring catheter was also documented.

For patients who had certified $\mathrm{BD}$, the time from admission to the PICU until BD certification (in days), the time from BD until organ procurement (in hours), and the length of stay at the PICU were recorded and analyzed.

Ancillary methods considered to certify $\mathrm{BD}$, conducted by the regulatory agency or the institute where the patient was staying, included apnea test (absence of spontaneous breathing with partial pressure of carbon dioxide $\left[\mathrm{PaCO}_{2}\right]$ $>60 \mathrm{mmHg}$ ), electroencephalogram, multimodal evoked potentials (somatosensory, brainstem auditory, and visual with electroretinography), and methods to assess blood flow to the brain (transcranial Doppler sonography, cerebral angiography, computed tomography [CT] angiography and cerebral perfusion or angiogammagraphy with Tc99-HMPAO).

Alterations inherent to BD were analyzed, such as hyperglycemia (blood glucose $>180 \mathrm{mg}$ / $\mathrm{dL})$, hypothermia $\left(<35^{\circ} \mathrm{C}\right)$, diabetes insipidus (polyuria, urine density $<1005$, and hypernatremia [Na $>145 \mathrm{mEq} / \mathrm{dL}]$ ), coagulopathy (prothrombin time $<60 \%$ ), and hemodynamic dysfunction (mean blood pressure $<2$ standard deviations [SD] from the $50^{\text {th }}$ percentile for the age and/or inotrope or vasopressor requirements or increased dosage).

Finally, data of patients with BD were analyzed and compared to the INCUCAI's records to establish the verdict made by the agency in relation to potential donors and assess the extent of effective donation achieved.

Patients with certified BD were classified as not approached, if cardiac arrest occurred before the assessment by the regulatory agency or if the assessment process was carried out before the agency made a verdict; approached, if the INCUCAI started the assessment process because they were considered potential donors and it made a verdict. Patients who were approached but then rejected were grouped as not suitable, if they were excluded as potential donors as a result of their underlying disease or based on the clinical conditions that followed BD, or family refusal, if the patient's family stated so. 


\section{Analysis plan}

The statistical analysis was done using the STATA 9.0 software for Windows ${ }^{\circledR}$ (StataCorp, College Station, Texas, USA). Based on outcome measure distribution, either normal or abnormal, values were expressed as mean and SD or as median and interquartile range.

\section{RESULTS}

In the study period, a total of 10541 admissions were recorded at the PICUs where the study was conducted, with an overall mortality of $7.45 \%(\mathrm{~N}=768)$. The clinical BD criteria were met by $19.14 \%(\mathrm{~N}=147)$ of patients; BD was certified by ancillary methods in 103 patients, which corresponded to $13.4 \%$ of all deaths (see Figure 2). For the analysis of demographic data, all patients who met the clinical criteria of $\mathrm{BD}(\mathrm{N}=147)$ were considered; their median age was 84 months (26-144).

The most common diagnosis as BD cause was multiple trauma in $26.5 \%(\mathrm{~N}=39)$ of patients (see Table 1).

Among patients with certified BD, the time from admission to the PICU until BD diagnosis was 2 days (0.8-5); organ maintenance lasted 24 hours (12-24); and the length of stay at the PICU was 3 days (1.5-6).
In relation to the ancillary methods used to certify $\mathrm{BD}$, the combination of electroencephalogram and apnea test to assess brain cortex and stem, respectively, was the most commonly used method, in $65 \%$ of patients $(\mathrm{N}=67)$ (see Table 1).

Regarding alterations that follow BD, 92 alterations were observed among 103 patients (see Table 1). Thirty-eight patients $(36.9 \%$ ) had 3 or more associated complications.

Out of 103 patients with BD certified by ancillary methods, 16 were classified as not approached. Among the 87 patients who were approached by INCUCAI and who started the potential donor process, $59(67.8 \%)$ were ruled out as donors by the supervising agency, 35 because they were not suitable and 24 because of family refusal. Among the 28 patients with certified BD who met donor criteria, 26 underwent the procedure (median age: 10 ), whereas the remaining donors were rejected due to lack of adequate receptor. Out of the 26 donors, 19 were actual donors, defined as those who donated solid organs and tissues, whereas the remaining 7 patients donated tissues.

Seventy-two patients benefited from solid organ transplantation and 50 received or will potentially receive tissue grafts.

TABLE 1. Main characteristics related to brain death diagnosis

\begin{tabular}{|c|c|}
\hline Outcome measures & Number and percentage $(\%)$ \\
\hline \multicolumn{2}{|c|}{ Causes of brain death among all patients who met the clinical criteria $(\mathrm{N}=147)$} \\
\hline Multiple trauma & $39(26.5 \%)$ \\
\hline Hypoxia/cerebral ischemia & $37(25.2 \%)$ \\
\hline Stroke & $25(17 \%)$ \\
\hline Central nervous system infection & $21(14.3 \%)$ \\
\hline Central nervous system tumor & $13(8.8 \%)$ \\
\hline Liver failure & $7(4.7 \%)$ \\
\hline Other & $5(3.4 \%)$ \\
\hline Patients with intracranial hypertension & $32(21.8 \%)$ \\
\hline \multicolumn{2}{|c|}{ Ancillary methods for patients with certified brain death $(\mathrm{N}=103)$} \\
\hline Electroencephalogram & $96(93.2 \%)$ \\
\hline Apnea test & $71(68.9 \%)$ \\
\hline Multimodal evoked potentials & $18(17.4 \%)$ \\
\hline Transcranial Doppler sonography & $17(16.5 \%)$ \\
\hline Assessment of brain flow by MNR or CT angiography & $10(9.7 \%)$ \\
\hline \multicolumn{2}{|c|}{ Alterations that follow brain death $(\mathrm{N}=103)$} \\
\hline Hemodynamic dysfunction & $65(63.2 \%)$ \\
\hline Diabetes insipidus & $48(46.6 \%)$ \\
\hline Hypothermia & $47(45.6 \%)$ \\
\hline Hyperglycemia & $31(30.1 \%)$ \\
\hline Coagulation disorders & $19(18.4 \%)$ \\
\hline
\end{tabular}

CT: computed tomography; MNR: magnetic nuclear resonance. 


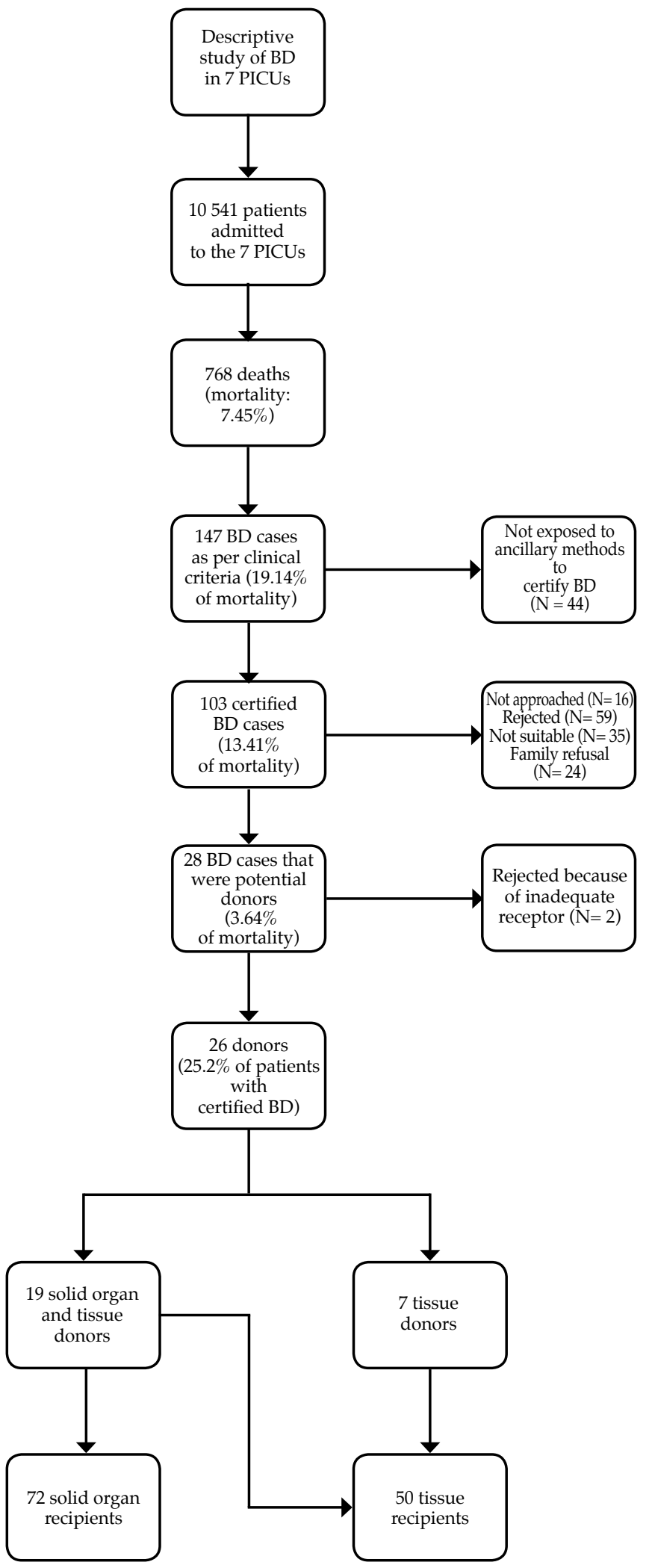

BD: brain death; PICU: pediatric intensive care unit. 


\section{DISCUSSION}

The incidence of certified BD $(\mathrm{N}=103)$ at the 7 PICUs that participated in the study was $1 \%$ of all admissions, which accounted for $13.4 \%$ of mortality, similar to the values observed in other international studies ${ }^{3,9}$ and in a multicenter study conducted in Argentina that included 16 PICUs and determined that BD accounted for $11 \%$ of deaths (52 out of 448). ${ }^{11}$

Multiple trauma was the main cause of BD, a characteristic also noted in the publications by González ${ }^{4}$ and Joffe, ${ }^{9}$ with a median age of 7 years old, far above the age indicated by Burns ${ }^{3}$ ( 2 years old) and similar to that reported by Gündüz $z^{5}$ and, again, Joffe. ${ }^{9}$

BD certification using ancillary methods is mandatory in Argentina, ${ }^{1}$ contrary to what occurs in the USA, Canada, Australia, and some European and Ibero-American countries, ${ }^{12}$ where BD may be certified by clinical examination. ${ }^{6}$ It is worth noting that, in this study, $30 \%$ of cases of clinical BD (44 out of 147) were not certified using ancillary methods, which harbors the potential for lost donors, which is higher than what has been reported by a multicenter study conducted in Brazil, ${ }^{13}$ which showed that $20 \%$ of BD cases were not certified. It has been considered that the implications of adopting a health policy in relation to mandatory ancillary methods are subjected to ethical and cultural conditions inherent to each country and are worth discussing in the scientific society as a whole. In this study, electroencephalograms and apnea tests were the most common methods used to certify BD, which have been also reported in other publications. ${ }^{4,5,9}$

In relation to the time elapsed since BD diagnosis, in the cases reported in this study, it was 24 hours (median). There is disparity in relation to these values in the bibliography: González ${ }^{4}$ described 8 hours and Gündüz, ${ }^{5}$ 6 days. The importance of assessing this outcome measure is supported by the alterations that follow $\mathrm{BD}$, which require interventions to maintain the viability of the organs to be procured. In this study, $89 \%$ of BD cases developed alterations; the most common ones were hemodynamic dysfunction, ${ }^{14}$ diabetes insipidus, and hypothermia, which was consistent with the bibliography. 4,5 Another aspect that reveals the difficulty in the determination of the time elapsed since BD diagnosis is the difficulty of withdrawing vital support among non-donors, a characteristic reflected in the study by Althabe, ${ }^{11}$ where mechanical ventilation was maintained in
$100 \%$ of cases, and inotrope support, in $82 \%$.

At the initiation of the study period, the percentage of patients $<18$ years accounted for $1 \%$ of all patients in the INCUCAI's waiting list, which increased to $2.6 \%$ by the time the study ended, a value that has also been observed in other countries, such as the USA $(1.5 \%)$ and the United Kingdom (2\%). ${ }^{6}$ It is worth noting that the above mentioned increase is not parallel to the number of donors, therefore increasing unmet needs in this age group.

In our series, $25 \%$ of patients with certified BD were donors $(26 / 103)$ and $18 \%$ donated solid organs (19/103), a percentage that is much higher than that observed in the study by Lago, ${ }^{13}$ which revealed a total of 525 deaths in 7 PICUs, 61 BD cases and only 6 donors; whereas in the United Kingdom, ${ }^{15}$ a study conducted in 26 hospitals, with a total of 189 BD cases (16.7\% of deaths), solid organ donation was achieved in $24.3 \%$ of cases. In that study, ${ }^{15}$ patients were classified into 2 groups, those with BD, which included 37 donors, and a second group categorized as "non-beating heart," which included 9 donors; such higher values are evidenced in the report by Morris, ${ }^{16}$ who conducted a study at 25 PICUs in the United Kingdom among patients with severe traumatic brain injury, where 12 out of 26 patients with BD were donors.

In our series, a total of 72 solid organs from 19 donors were implanted, with a recipient/ donor ratio close to 4 , which is comparable to the series conducted by Ream, ${ }^{8}$ who divided organ performance by age group: 3.5 and 4.9 for groups aged $0-10$ and $11-17$ years, respectively. Such relation was 2.5 (114 recipients / 46 donors) in the series carried out by Brierley. ${ }^{15}$

Family refusal was the reason for rejection in $40 \%$ of cases (24/59), which was higher than what has been observed in other series (20-30\%).9,10,17 The causes for such refusal were not analyzed in this study but it is worth noting that it reflects a lack of society awareness and education, and calls for the standardization of efforts aimed at reversing this tendency, and the need to access family opinions about donation in advance.

Organ procurement is the process of collecting organs and tissues for transplantation in order to meet the needs of patients in the waiting list. This process is made up of several, diverse logistical steps in a systematic manner which requires coordinated actions at each stage. The different research lines related to the organ management process look to optimize the process to fulfill 
an unmet demand. In this regard, in Argentina, different programs have been implemented to identify potential donors. One was called Coordinador Hospitalario (Hospital Coordinator), which helped to double the number of organ procurements in the 2003-2010 period, but then showed a downward trend. In 2013, a program called Hospital Donante (Donor Hospital) was launched as a strategy to institutionalize organ procurement at hospitals; however, results were not able to achieve a cultural change in the health care system. Thus, the new plan of the regulatory agency is to transform the out-of-hospital procurement model into one where the hospital takes over the donation-transplantation process in full. This has already been implemented in other countries, ${ }^{8}$ where multiple organizations are responsible for organ procurement management.

It is worth mentioning that, when this study ended, the organ waiting list included 288 patients younger than 18 years; 57 required corneas and sclera and 231, solid organs, and 32\% were younger than 10 years.

This study aimed at making a diagnosis of the situation in relation to the organ management process in Argentina, especially because there is no other study in the national bibliography that focuses on the effectiveness of this process and because of the limitations of accessing these results retrospectively, which may have resulted in under-recording.

\section{CONCLUSION}

Clinical BD accounted for $19.1 \%$ of deaths whereas certified BD, for $13.4 \%$. A total of $15.5 \%$ of certified BD cases were not approached by the regulatory agency.

Effective donors, those for whom the transplantation process was completed, accounted for $25 \%$ of patients with certified BD (26/103); 19 of these 26 cases effectively donated solid organs and tissue and 7, only tissue.

\section{REFERENCES}

1. Abaroa L, Garretto N. Muerte encefálica. Situación legal en Argentina. Neurolog Argent 2013;5(2):101-7.

2. Protocolo nacional para certificar el diagnóstico de muerte bajo criterios neurológicos (muerte encefálica). Ministerio de Salud. Resolución No 275/2010 - Boletín oficial 2010;31844. [Accessed on: August 18 ${ }^{\text {th }}, 2016$ ]. Availableat:http:/ / www.cucaiba.gba.gov.ar/viejo/2013/ pdf_2013/2013_protocolo_muerte.pdf.

3. Burns J, Sellers D, Meyer E, et al. Epidemiology of Death in the PICU at Five U.S. Teaching Hospitals. Crit Care Med 2014;42(9):2101-8.

4. González N, Fernández M, Galán C, et al.Muerte encefálica y donación en población infantil. An Pediatr (Barc) 2004;60(5):450-3.

5. Gündüz R, Şahin S, Uysal-Yazıcı M, et al. Brain death and organ donation of children. Turk J Pediatr 2014;56(6): 597603.

6. Brierley J, Hasan A. Aspects of deceased organ donation in paediatrics. Br J Anaesth 2012;108 (Suppl 1):i92-5.

7. Workman J, Craig WM, Meyers R, et al. Pediatric Organ Donation and Transplantation. Pediatrics 2013;131(6): e1723-30.

8. Ream R, Armbrecht E. Survey of U.S. Organ Procurement Organizations Regarding Pediatric Organ Donor Management. Pediatr Crit Care Med 2016;17(10):e459-68.

9. Joffe A, Shemie S, Farrell C, et al. Brain death in Canadian PICUs: Demographics, timing, and irreversibility. Pediatr Crit Care Med 2013;14(1):1-9.

10. Toida C, Muguruma T. Pediatric brain death in a Japanese pediatric hospital. Acute Med Surg 2016;3(1):10-5.

11. Althabe M,Cardigni G, VassaloJ, etal. Dying in the Intensive Care Unit: collaborative multicenter study about forgoing life-sustaining treatment in Argentine Pediatric Intensive Care Units. Pediatr Crit Care Med 2003;4(2):164-9.

12. Escudero D, Matesanz R, Soratti C, et al. Muerte encefálica en Iberoamérica. Med Intensiva 2009;33(9):415-23.

13. Lago P, Piva J, Garcia P, et al. Brain death: medical management in seven Brazilian pediatric intensive care units. J Pediatr (Rio J) 2007;83(2):133-40.

14. Krishnamoorthy V, Borbely X, Rowhani-Rahbar A, et al. Cardiac dysfunction following brain death in children: prevalence, normalization, and transplantation. Pediatr Crit Care Med 2015;16(4):e107-12.

15. Brierley J. Paediatric organ donation in the UK. Arch Dis Child 2010;95(2):83-8.

16. Morris K, Tasker R, Parslow R, et al. Organ donation in pediatric traumatic brain injury. Intensive Care Med 2006;32(9):1458.

17. Tsai E, Shemie $\mathrm{S}, \mathrm{Cox} \mathrm{P}$, et al. Organ donation in children: role of the pediatric intensive care unit. Pediatr Crit Care Med 2000;1(2):156-60. 